\title{
Survival of patients with Kaposi's sarcoma in the South African antiretroviral treatment era: A retrospective cohort study
}

\author{
M M Sengayi, ${ }^{1,2,3}$ MB ChB, Dip HIV Man, PhD; D Kielkowski, ${ }^{1}$ PhD; M Egger, ${ }^{4,5}$ MD, MSc, FFPH (UK); \\ L Dreosti, ${ }^{6} \mathrm{MB}$ ChB, BSc Hons, FCP (SA); J Bohlius, ${ }^{4} \mathrm{MD}, \mathrm{MScPH}$ \\ ${ }^{1}$ National Cancer Registry, National Health Laboratory Service, Johannesburg, South Africa \\ ${ }^{2}$ Graduate School for Cellular and Biomedical Sciences, University of Bern, Switzerland \\ ${ }^{3}$ School of Public Health, Faculty of Health Sciences, University of the Witwatersrand, Johannesburg, South Africa \\ ${ }^{4}$ Institute of Social and Preventive Medicine, University of Bern, Switzerland \\ ${ }^{5}$ Centre for Infectious Disease Epidemiology and Research, School of Public Health and Family Medicine, Faculty of Health Sciences, \\ University of Cape Town, South Africa \\ ${ }^{6}$ Department of Medical Oncology, Steve Biko Academic Hospital and School of Medicine, Faculty of Health Sciences, University of Pretoria, \\ South Africa
}

Corresponding author: M M Sengayi (mazvita.sengayi@nhls.ac.za)

\begin{abstract}
Background. When South Africa (SA) implemented its antiretroviral therapy (ART) programme in 2004, the model for treating HIVpositive Kaposi's sarcoma (KS) patients shifted from symptomatic palliation to potential cure.

Objective. To evaluate survival and changes over time in AIDS-KS patients treated at a tertiary academic hospital oncology unit (the Steve Biko Academic Hospital medical oncology unit) in Pretoria, SA, in the context of ART availability in SA.

Methods. We conducted a retrospective review of electronic and paper records of KS patients who accessed cancer care between May 2004 and September 2012. We used Kaplan-Meier survival functions to estimate 1- and 2-year survival, and Cox regression models to identify changes over time and prognostic factors.

Results. Our study included 357 AIDS-KS patients, almost all of whom were black Africans ( $n=353,98.9 \%) ; 224$ (62.7\%) were men. The median age at cancer diagnosis was 37 (interquartile range (IQR) 30 - 43) years, and the median baseline CD4+ count was 242 (IQR 130 403) cells/ $\mu \mathrm{L}$. Most patients received ART ( $n=332,93.0 \%)$ before or after KS diagnosis; 169 (47.3\%) were treated with chemotherapy and 209 (58.6\%) with radiation therapy. Mortality was $62.7 \%$ lower (adjusted hazard ratio (HR) $0.37,95 \%$ confidence interval (CI) $0.19-0.73$ ) in the late (2009 - 2012) than in the early (2004 - 2008) ART period. Receiving chemotherapy (adjusted HR 0.3, 95\% CI 0.15 - 0.61 ) and poor-risk AIDS Clinical Trials Group KS stage (adjusted HR 2.88, 95\% CI 1.36 - 6.09) predicted mortality.

Conclusions. Our results show that large national ART roll-out programmes can successfully reduce KS-related mortality at the individual patient level. If ART coverage is extended, KS-associated morbidity and mortality are likely to drop.
\end{abstract}

S Afr Med J 2017;107(10):871-876. DOI:10.7196/SAMJ.2017.v107i10.12362

When the South African (SA) antiretroviral therapy (ART) programme was rolled out in 2004, the treatment model for HIVpositive Kaposi's sarcoma (KS) patients shifted from symptomatic palliation to potential cure. ${ }^{[1]}$ The advent of ART dramatically decreased KS incidence, morbidity and mortality in high-income countries. ${ }^{[2-4]}$ SA addressed its large HIV epidemic by implementing a national ART programme, ${ }^{[5-7]}$ but studies in the early ART era showed that KS morbidity and mortality were still high in SA, largely because ART coverage was still too low, and patients with KS were diagnosed late and many who needed chemotherapy did not receive it. ${ }^{[8]}$

While ART can bring about remission in early-stage KS, advanced KS requires systemic chemotherapy ${ }^{[9]}$ The Kaposi sarcoma AIDS Antiretroviral Therapy (KAART) trial in Durban showed 1-year overall survival rates of $77 \%$ in patients who received ART alone and those who received ART and chemotherapy (doxorubicin, bleomycin and vincristine), with no significant survival difference between the two treatment arms. ${ }^{[9]}$ This and other studies suggest that in the context of ART and affordable standard-of-care cancer regimens, KS in HIV-positive patients can be treated effectively in resource-limited settings. ${ }^{[9,10]}$

\section{Objective}

The SA national ART programme grew rapidly after it was implemented in 2004. We sought to determine whether improved ART availability has begun to have a positive effect on the survival rate of HIV-positive KS patients in routine oncology care in the Steve Biko Academic Hospital (SBAH) medical oncology unit, a tertiary academic medical oncology unit in Pretoria, SA. We estimated survival rates in KS patients and changes over time, comparing the early $(2004$ - 2008) with the late $(2009$ - 2012) ART period.

\section{Methods}

\section{Study design and setting}

We retrospectively reviewed electronic and paper records of KS patients who accessed treatment at the SBAH medical oncology unit. Patients are referred to SBAH from northern Gauteng (Tshwane District, Mamelodi, Tembisa, Kalafong, Weskoppies and Bronkhorstspruit hospitals) and Mpumalanga (Witbank, Nelspruit, Philadelphia and Groblersdal hospitals) provinces. All HIV-positive KS patients were referred for ART and reviewed for eligibility for chemotherapy and/or radiation therapy after taking ART for at least 
3 months. SBAH staff followed up patients who missed their visits by phone, and confirmed vital status (based on national identification number) with the SA Department of Home Affairs as part of routine care.

\section{Participants}

We included all adult patients ( $\geq 18$ years) with clinically or histologically diagnosed KS who accessed oncology care at the SBAH medical oncology unit between May 2004 and September 2012. We excluded HIV-negative patients and those whose HIV status was unknown. Data on eligible KS patients were extracted from the SBAH medical oncology unit's electronic database. We used a data collection form to capture additional information from paper records. We extracted the following data: demographic characteristics, baseline CD4+ count, HIV RNA viral load, haemoglobin concentration, other HIV-related comorbidities, date of KS diagnosis, KS site, AIDS Clinical Trials Group (ACTG) KS stage, ${ }^{[11,12]}$ HIV status, ART use, date of starting ART, chemotherapy and radiation therapy, date of last visit, and patient outcome. Outcomes were defined as alive and in care at SBAH, referred/transferred to another facility, death, confirmed loss to follow-up ( $>6$ months from missed scheduled visit, but confirmed to be alive through Home Affairs) and unknown outcome ( $>6$ months from missed scheduled visit, but vital status unknown). Patients who were alive and in care at SBAH or referred/ transferred to another facility were classified as retained in care. Data were captured with EpiData software (EpiData version 3.1, EpiData Association, Denmark).

\section{Data analysis}

Patient characteristics by ART period were described with frequencies, medians and interquartile ranges (IQRs). Time was measured from date of KS diagnosis to date of death or last clinic visit. We used Kaplan-Meier survival functions to estimate overall survival and survival by ART period at 1 and 2 years' follow-up. We also estimated survival and retention in care at 1 and 2 years' follow-up. We used uni- and multivariable Cox regression models to determine changes over calendar years, defined as early (2004 - 2008) v. late (2009 - 2012) ART periods. In the multivariable Cox model, we adjusted the effect of ART period for gender, age, baseline CD4+ count, ACTG KS stage, history of tuberculosis (TB) infection, ART status at KS diagnosis, chemotherapy and radiation therapy. We performed multiple imputation, using chained equations to correct for missing ACTG KS stage (26.0\% missing), baseline CD4+ count (11.5\% missing) and baseline haemoglobin $(8.1 \%$ missing) in the multivariable model. In sensitivity analyses, we fitted Cox regression models for the composite outcome of mortality and loss to follow-up. All analyses were done using Stata version 13 (Stata Corporation, USA).

\section{Ethics approval}

Informed consent was sought from all cancer patients in the SBAH medical oncology unit, requesting the use of their deidentified medical records for research publication. Ethics approval was granted by the University of Pretoria Faculty of Health Sciences Research Ethics Committee (ref. no. 199/2012).

\section{Results}

\section{Characteristics of patients with AIDS-KS and} changes over time

Between May 2004 and September 2012, a total of 374 KS patients received oncology care in the SBAH medical oncology unit. We excluded 13 HIV-negative patients (3.5\%) and four patients of unknown HIV status (1.1\%). We included all 357 HIV-positive patients
$(95.5 \%)$ in the analysis. Most ( $n=353,98.9 \%)$ were black Africans, and $62.7 \%$ were men. The median age was 38 (IQR $31-45$ ) years for men and 34 (IQR 29 - 41) years for women (Table 1). The median baseline CD4+ count was 242 (IQR 130 - 403) cells $/ \mu \mathrm{L}$ and the median baseline haemoglobin concentration 10.7 (IQR $9-12.5) \mathrm{g} / \mathrm{dL}$. Of included patients, $25.2 \%(n=90)$ had a documented history of TB infection. Most patients had histologically confirmed KS ( $n=355,99.4 \%)$. KS lesions were most commonly found on the lower limbs $(n=281$, $78.7 \%)$ and $35.0 \%$ of patients $(n=125)$ had oedema. About a quarter of the patients $(n=93,26.0 \%)$ were not staged. Of those with ACTG staging, 68.2\% (180/264) had ACTG poor-risk stage. At the time of KS diagnosis, $64.1 \%(n=229)$ were on ART; another 103 started ART after KS diagnosis. Most patients received ART ( $n=332,93.3 \%)$, nearly half $(n=169,47.3 \%)$ received chemotherapy, and 209 (58.5\%) received radiation therapy. Of those who received ART, 66 (19.9\%) received only ART, 67 (20.2\%) received ART and chemotherapy, 97 (29.2\%) received ART, chemotherapy and radiation, and 102 (30.7\%) received ART and radiation therapy. Of the 169 patients who received chemotherapy, 145 $(85.8 \%)$ were treated with doxorubicin-bleomycin-vincristine (ABV) and 24 (14.2\%) with oral etoposide (VP16).

The median follow-up time over the whole study period was 9.6 (IQR 2.2 - 23) months.

Compared with the early ART period (2004-2008), patients diagnosed with KS in the late ART period (2009 - 2012) had, on average, higher CD4+ cell counts than those diagnosed in the early period $(250$ v. 233 cells $/ \mu \mathrm{L})$. Patients in the late ART period also had lower HIV RNA viral loads (median 3.2 v. $7.6 \log _{10}$ copies $/ \mathrm{mL}$ ), and were more often on ART at KS diagnosis ( $72.7 \%$ v. $53.8 \%)$. In the later period, only $2.5 \%$ of patients received no ART before or after diagnosis; $12.1 \%$ had received no ART in the early period. The proportion of patients who received chemotherapy or radiotherapy did not change over time. Patients diagnosed in the late period were more likely to be male $(66.7 \%$ v. $57.9 \%)$ and more likely to be diagnosed at advanced ACTG KS stages (56.6\% v. $42.8 \%$ ). The proportion of unstaged patients decreased from $31.4 \%$ in the early period to $21.7 \%$ in the late period.

\section{Survival and retention in care}

At end of the study period, 181 patients (50.7\%) were alive and in care at SBAH, 95 (26.6\%) had died, 39 (10.9\%) were lost to followup ( $>6$ months from missed scheduled visit, but confirmed to be alive through Home Affairs), 23 (6.4\%) had unknown outcomes ( $>6$ months from missed scheduled visit, but vital status unknown), and $19(5.3 \%)$ were discharged or transferred. Overall survival in all patients at 1 and 2 years' follow-up was $78.5 \%$ (95\% confidence interval (CI) 72.9 - 83.0) and 66.7\% (95\% CI 59.8 - 72.8), respectively. Patients diagnosed in the late ART period had higher survival rates than those diagnosed in the early ART period. One-year survival was $72.0 \%(95 \%$ CI $63.3-83.0)$ in the early period and $84.6 \%(95 \%$ CI 77.5 - 89.6) in the late period, while 2-year survival was $55.8 \%$ (95\% CI 45.8 - 64.7) in the early period and $79.0 \%$ (95\% CI 69.9 85.6) in the late period (Table 2). Likewise, patients diagnosed in the late ART period had higher survival and retention rates than those diagnosed in the early ART period (Fig. 1). One-year survival and retention was $60.4 \%$ (95\% CI 51.8 - 67.9) in the early period and $72.3 \%$ (95\% CI 64.3 - 78.8) in the late period, while 2-year survival and retention was $39.8 \%(95 \%$ CI $31.3-48.1)$ in the early period and $66.7 \%$ (95\% CI 57.6 - 74.2) in the late period (Table 2). Patients who received chemotherapy had higher survival and retention rates than those who did not. One-year survival and retention was 50.5\% (95\% CI 41.9 - 58.4) in the patients who did not receive chemotherapy and 83.2\% (95\% CI 75.9 - 88.4) in the patients who did receive it, while 


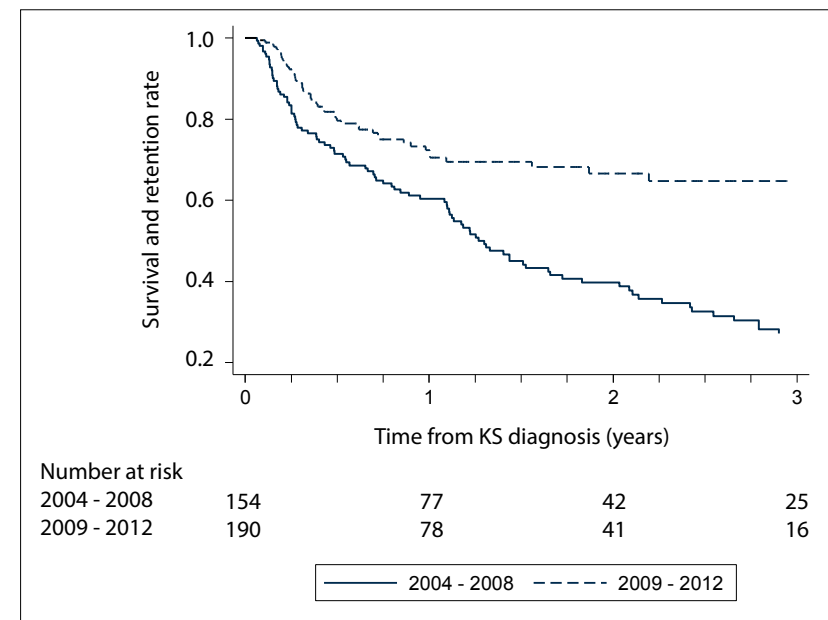

Fig. 1. Survival and retention in oncology care by calendar period. $(K S=$ Kaposi's sarcoma.) 2-year survival and retention was $36.8 \%$ (95\% CI 28.1 - 45.6) in the patients who did not receive chemotherapy and 66.9\% (95\% CI 57.5 74.7) in those who did receive it.

\section{Changes over time and predictors of mortality}

In univariable analyses, patients in the late period were more likely to survive than those in the early period (hazard ratio (HR) $0.41,95 \%$ CI 0.26 - 0.64) (Table 3). We confirmed this association (HR 0.37, 95\% CI 0.19 - 0.73) after adjusting for age, gender, baseline CD4+ count, baseline haemoglobin, ACTG KS stage, TB comorbidity, ART use at KS diagnosis, chemotherapy and radiation therapy. In both univariable and multivariable analyses, ACTG poor-risk stage (adjusted HR 2.88, 95\% CI 1.36 - 6.09) was associated with increased mortality. A previous history of TB was associated with mortality in univariable (HR 1.64, 95\% CI 1.05 - 2.57) but not in multivariable analyses. Receiving chemotherapy was associated with better survival in both univariable and multivariable analyses (adjusted HR 0.30, 95\% CI 0.15 - 0.61). After correction for missing data, radiation

\section{Table 1. Patient characteristics}

\begin{tabular}{|c|c|c|c|}
\hline & \multicolumn{3}{|c|}{ Calendar period of KS diagnosis } \\
\hline & $\begin{array}{l}\begin{array}{l}\text { Early ART period, } \\
2004-2008(N=159)\end{array} \\
\end{array}$ & $\begin{array}{l}\text { Late ART period, } \\
2009-2012(N=198) \\
\end{array}$ & Total, 2004 - $2012(N=357)$ \\
\hline \multicolumn{4}{|l|}{ Demographic characteristics } \\
\hline Males, $n(\%)$ & $92(57.9)$ & $132(66.7)$ & $224(62.7)$ \\
\hline \multicolumn{4}{|l|}{ Age at KS diagnosis (yr), median (IQR) } \\
\hline All patients & $36(30-45)$ & $37(31-42)$ & $37(30-43)$ \\
\hline Males & $38(31-47)$ & $37(32-42)$ & $38(31-45)$ \\
\hline Females & $33(30-42)$ & $34(28-41)$ & $34(29-41)$ \\
\hline Black Africans, $n$ (\%) & $156(98.1)$ & $197(99.5)$ & $353(98.9)$ \\
\hline \multicolumn{4}{|l|}{ Clinical characteristics } \\
\hline CD4+ count (cells/ $\mu \mathrm{L})$, median (IQR) & $233(136-396)$ & $250(124-409)$ & $242(130-403)$ \\
\hline HIV viral load ( $\log _{10}$ copies/mL) & $7.6(3.2-12.1)$ & $3.2(3.2-5.7)$ & $3.2(3.2-10.2)$ \\
\hline Baseline haemoglobin (g/dL), median (IQR) & $10.7(9.1-12.4)$ & $10.8(8.9-12.6)$ & $10.7(9-12.5)$ \\
\hline TB comorbidity, $n(\%)$ & $37(23.3)$ & $53(26.8)$ & $90(25.2)$ \\
\hline Histological diagnosis, $n$ (\%) & $158(99.4)$ & $197(99.5)$ & $355(99.4)$ \\
\hline \multicolumn{4}{|l|}{ Site of KS lesions, $n(\%)$} \\
\hline Upper limbs & $34(21.4)$ & $51(25.8)$ & $85(23.8)$ \\
\hline Lower limbs & $119(74.8)$ & $162(81.8)$ & $281(78.7)$ \\
\hline Oral & $42(26.4)$ & $37(18.7)$ & $79(22.1)$ \\
\hline Head & $30(18.9)$ & $52(26.3)$ & $82(23.0)$ \\
\hline Trunk & $35(22.0)$ & $42(21.2)$ & $77(21.6)$ \\
\hline Lymph nodes & $9(5.7)$ & $7(3.5)$ & $16(4.5)$ \\
\hline Gastrointestinal & $3(1.9)$ & $1(0.5)$ & $4(1.1)$ \\
\hline Lung* & $34(21.4)$ & $23(11.6)$ & $57(16)$ \\
\hline Groin & $11(6.9)$ & $33(16.7)$ & $44(12.3)$ \\
\hline Disseminated skin lesions & $13(8.2)$ & $30(15.1)$ & $43(12.0)$ \\
\hline Presence of oedema & $46(28.9)$ & $79(39.9)$ & $125(35.0)$ \\
\hline \multicolumn{4}{|l|}{ ACTG staging, $n(\%)$} \\
\hline Good risk & $41(25.8)$ & $43(21.7)$ & $84(23.5)$ \\
\hline Poor risk & $68(42.8)$ & $112(56.6)$ & $180(50.4)$ \\
\hline Not staged & $50(31.4)$ & $43(21.7)$ & $93(26.0)$ \\
\hline \multicolumn{4}{|l|}{ KS treatment, $n(\%)$} \\
\hline On ART at KS diagnosis & $85(53.8)$ & $144(72.7)$ & $229(64.3)$ \\
\hline Ever received ART & $139(87.9)$ & $193(97.5)$ & $332(93.3)$ \\
\hline Received chemotherapy & $72(45.3)$ & $97(49.0)$ & $169(47.3)$ \\
\hline Received radiation therapy & $91(57.2)$ & $118(59.6)$ & 209 (58.5) \\
\hline
\end{tabular}


Table 2. Overall survival and retention in care at 1 and 2 years after KS diagnosis

\begin{tabular}{|c|c|c|}
\hline & Early ART era (2004 - 2008), \% (95\% CI) & Late ART era $(2009$ - 2012), \% (95\% CI) \\
\hline \multicolumn{3}{|c|}{ Overall survival } \\
\hline At 1 year & $72.0(63.3-83)$ & $84.6(77.5-89.6)$ \\
\hline At 2 years & $55.8(45.8-64.7)$ & $79.0(69.9-85.6)$ \\
\hline \multicolumn{3}{|c|}{ Overall survival and retention in care } \\
\hline At 1 year & $60.4(51.8-67.9)$ & $72.3(64.3-78.8)$ \\
\hline At 2 years & $39.8(31.3-48.1)$ & $66.7(57.6-74.2)$ \\
\hline
\end{tabular}

Table 3. Predictors of mortality in patients diagnosed with KS

\begin{tabular}{|c|c|c|c|}
\hline & $\begin{array}{l}\text { Univariable analysis, } \\
\text { HR }(95 \% \mathrm{CI})\end{array}$ & $\begin{array}{l}\text { Multivariable complete case } \\
\text { analysis, } \mathrm{HR}(95 \% \mathrm{CI})\end{array}$ & $\begin{array}{l}\text { Multivariable imputed } \\
\text { model, HR }(95 \% \mathrm{CI})\end{array}$ \\
\hline \multicolumn{4}{|l|}{ Gender } \\
\hline Male & 1 & 1 & 1 \\
\hline Female & $0.92(0.60-1.41)$ & $0.85(0.46-1.60)$ & $0.71(0.44-1.15)$ \\
\hline Age & $0.98(0.95-0.99)$ & $0.97(0.94-1.01)$ & $0.98(0.95-1.00)$ \\
\hline \multicolumn{4}{|l|}{ ART period } \\
\hline Early (2004 - 2008) & 1 & 1 & 1 \\
\hline Late $(2009-2012)$ & $0.41(0.26-0.64)$ & $0.37(0.19-0.73)$ & $0.37(0.23-0.60)$ \\
\hline \multicolumn{4}{|l|}{ Baseline CD4+ count (cells/ $\mu \mathrm{L})$} \\
\hline$<100$ & 1 & 1 & 1 \\
\hline $100-199$ & $0.82(0.43-1.58)$ & $0.77(0.30-2.01)$ & $0.80(0.40-1.62)$ \\
\hline $200-349$ & $0.80(0.43-1.51)$ & $1.17(0.45-3.02)$ & $1.14(0.57-2.27)$ \\
\hline $350-500$ & $0.63(0.32-1.25)$ & $1.09(0.39-3.08)$ & $1.22(0.55-2.71)$ \\
\hline$>500$ & $0.54(0.24-1.21)$ & $0.83(0.27-2.56)$ & $0.81(0.35-1.89)$ \\
\hline \multicolumn{4}{|l|}{ ACTG KS stage } \\
\hline Good risk & 1 & 1 & 1 \\
\hline Poor risk & $2.36(1.25-4.43)$ & $2.88(1.36-6.09)$ & $2.07(1.13-3.77)$ \\
\hline \multicolumn{4}{|l|}{ TB comorbidity } \\
\hline No TB & 1 & 1 & 1 \\
\hline TB & $1.64(1.05-2.57)$ & $1.29(0.66-2.52)$ & $1.45(0.90-2.35)$ \\
\hline \multicolumn{4}{|l|}{ ART use } \\
\hline Not on ART at KS diagnosis & 1 & 1 & 1 \\
\hline On ART at KS diagnosis & $0.79(0.52-1.20)$ & $0.82(0.44-1.51)$ & $0.96(0.61-1.52)$ \\
\hline \multicolumn{4}{|l|}{ Chemotherapy } \\
\hline No & 1 & 1 & 1 \\
\hline Yes & $0.30(0.19-0.47)$ & $0.30(0.15-0.61)$ & $0.28(0.17-0.47)$ \\
\hline \multicolumn{4}{|l|}{ Radiation therapy } \\
\hline No & 1 & 1 & 1 \\
\hline Yes & $0.57(0.38-0.86)$ & $0.72(0.38-1.34)$ & $0.52(0.33-0.81$ \\
\hline Haemoglobin & $0.84(0.77-0.92)$ & $0.92(0.80-1.05)$ & $0.91(0.83-1.01)$ \\
\hline
\end{tabular}

therapy (HR 0.52, 95\% CI 0.33 - 0.81) was also associated with better survival in the multivariable analyses. HRs from the imputed model were similar to those from complete case analyses. In sensitivity analyses, predictors of the composite outcome of mortality and loss to follow-up were similar to predictors of mortality (Table 4).

\section{Discussion}

We found that survival of KS patients at the SBAH medical oncology unit has substantially improved in recent years. Mortality was $62.7 \%$ lower (adjusted HR 0.37, 95\% CI 0.19 - 0.73) in the late (2009 - 2012) than in the early (2004-2008) ART period. This reduction was independent of patient (age, gender), disease progression (baseline CD4+ count, ACTG KS stage) or treatment (ART status at KS diag- nosis, chemotherapy and radiotherapy) factors. Overall survival was $78.5 \%$ at 1 -year follow-up and $66.7 \%$ at 2 -year follow-up in KS patients receiving routine care in a tertiary hospital in Pretoria. The majority of patients continued to present with advanced KS at diagnosis.

We were the first to demonstrate that KS survival increased significantly after the advent of ART in an African setting. We found good survival rates of KS patients in routine care, treated with ART and chemotherapy (ABV or oral VP16) and/or radiotherapy for selected patients. The overall 1-year survival rate of $78.5 \%$ is comparable to survival estimates from other SA studies, ${ }^{[8,9,13]}$ including a clinical trial that used similar chemotherapy regimens. ${ }^{[9]}$ An observational study in the USA estimated 2-year survival rates 
Table 4. Predictors of mortality and loss to follow-up in patients diagnosed with KS

\begin{tabular}{|c|c|c|c|}
\hline & $\begin{array}{l}\text { Univariable analysis, } \\
\text { HR ( } 95 \% \mathrm{CI})\end{array}$ & $\begin{array}{l}\text { Multivariable complete case } \\
\text { analysis, HR }(95 \% \mathrm{CI})\end{array}$ & $\begin{array}{l}\text { Multivariable imputed model, } \\
\text { HR }(95 \% \mathrm{CI})\end{array}$ \\
\hline \multicolumn{4}{|l|}{ Gender } \\
\hline Male & 1 & 1 & 1 \\
\hline Female & $0.98(0.70-1.36)$ & $0.70(0.43-1.13$ & $0.76(0.53-1.10)$ \\
\hline Age & $0.99(0.97-1.00)$ & $0.99(0.96-1.01)$ & $0.98(0.96-1.00)$ \\
\hline \multicolumn{4}{|l|}{ ART period } \\
\hline Early (2004 - 2008) & 1 & 1 & 1 \\
\hline Late $(2009-2012)$ & $0.45(0.32-0.64)$ & $0.39(0.24-0.64)$ & $0.40(0.28-0.58)$ \\
\hline \multicolumn{4}{|l|}{ Baseline CD4+ count (cells $/ \mu \mathrm{L})$} \\
\hline$<100$ & 1 & 1 & 1 \\
\hline $100-199$ & $0.78(0.47-1.30)$ & $0.70(0.34-1.42)$ & $0.74(0.42-1.30)$ \\
\hline $200-349$ & $0.81(0.50-1.32)$ & $1.02(0.50-2.09)$ & $0.93(0.53-1.63)$ \\
\hline $350-500$ & $0.62(0.36-1.06)$ & $0.97(0.45-2.10)$ & $1.09(0.57-2.08)$ \\
\hline$>500$ & $0.51(0.27-0.97)$ & $0.73(0.31-1.72)$ & $0.78(0.39-1.54)$ \\
\hline \multicolumn{4}{|l|}{ ACTG KS stage } \\
\hline Good risk & 1 & 1 & 1 \\
\hline Poor risk & $2.37(1.46-3.83)$ & $2.71(1.53-4.79)$ & $1.89(1.19-3.03)$ \\
\hline \multicolumn{4}{|l|}{ TB comorbidity } \\
\hline No TB & 1 & 1 & 1 \\
\hline TB & $1.46(1.02-2.09)$ & $1.26(0.75-2.11)$ & $1.22(0.83-1.81)$ \\
\hline \multicolumn{4}{|l|}{ ART use } \\
\hline Not on ART at KS diagnosis & 1 & 1 & 1 \\
\hline On ART at KS diagnosis & $0.96(0.69-1.34)$ & $1.09(0.68-1.75)$ & $1.20(0.84-1.72)$ \\
\hline \multicolumn{4}{|l|}{ Chemotherapy } \\
\hline No & 1 & 1 & 1 \\
\hline Yes & $0.33(0.24-0.47)$ & $0.39(0.23-0.67)$ & $0.35(0.23-0.52)$ \\
\hline \multicolumn{4}{|l|}{ Radiation therapy } \\
\hline No & 1 & 1 & 1 \\
\hline Yes & $0.64(0.47-0.89)$ & $0.91(0.57-1.46)$ & $0.64(0.46-0.90)$ \\
\hline Haemoglobin & $0.86(0.80-0.92)$ & $0.92(0.83-1.02)$ & $0.93(0.86-1.01)$ \\
\hline
\end{tabular}

comparable to what we found in the late ART period in SA (81\% and $79 \%$, respectively). ${ }^{[14]}$ This suggests that ART in HIV-positive KS patients combined with standard-of-care chemotherapy regimens and/or radiotherapy in selected patients yields favourable survival outcomes and is a practical option in high-burden resource-limited settings. We confirmed the findings of other studies that advanced KS stage ${ }^{[10,11,15,16]}$ predicts mortality, while chemotherapy ${ }^{[8,17]}$ increases the chance of survival in KS patients. Unlike other SA studies, ${ }^{[13,18]}$ we found no gender differences in mortality. Our study showed that both chemotherapy and radiation therapy were associated with improved survival. We suggest that referral for oncology care be considered for KS patients with failure of regression of lesions on ART alone, and for those with advanced disease. Recording of KS surveillance data at lower-level clinics will allow estimation of prognosis of KS across different stages.

Our findings reflect the success of the national ART programme, but also underline the need to reduce KS-associated morbidity and mortality further through early ART initiation. During the study period (2004 - 2012) the ART eligibility criteria were a CD4+ count $<200 / \mu \mathrm{L}$ or a World Health Organization stage IV AIDS-defining condition. ${ }^{[19]}$ Adult ART coverage rose from $5.1 \%$ in 2004 to $79 \%$ in $2011,{ }^{[6,7]}$ and this improved ART coverage is reflected in the improved ART status of patients in the later ART period in our study. In spite of improved ART coverage, KS incidence in HIV-positive southern
Africans remains unacceptably high, even in patients on ART, ${ }^{[20]}$ because only patients with significant immune impairment were eligible for ART. This underscores the need and potential impact of the test-and-treat strategy that SA adopted from September 2016. ${ }^{[21]}$

\section{Study strengths and limitations}

Our study had several strengths and some weaknesses. The SBAH medical oncology unit has good paper and electronic record systems, traces defaulters by phone, and routinely confirms vital status with the SA Department of Home Affairs. This allowed us to ascertain deaths and document date of death, so that vital status was unknown in only 23 patients $(6.4 \%)$. KS was pathologically confirmed in nearly all patients $(n=355,99.4 \%)$. Most KS patients had a documented HIV result (370/374), so we could include $95 \%$ of all KS patients in the analyses. The retrospective nature of our study did result in missing data, but we corrected for this with multiple imputation and confirmed the findings from the complete case analyses (Table 3). The KS patients in our study were mostly black Africans between 20 and 50 years of age, which reflects national HIV prevalence distribution, where this key population has the highest HIV seroprevalence. ${ }^{[5,22]}$ There was potential for selection bias in our study. We conducted our study at a tertiary academic hospital that may provide better care than most other healthcare facility levels. There was potential for selecting patients who had survived long enough to go through the referral 
system, those who had better healthcare access and also those who were sick enough to warrant referral to a tertiary hospital. ${ }^{[23]}$ We had a total of $374 \mathrm{KS}$ patients over the 8-year study period, which is a very small number given the high incidence of KS in HIV-positive people in SA. It is likely that many patients with early-stage KS were never referred for oncology care and were treated with ART only at their local HIV clinics. Furthermore, SA is a middle-income country and access to cancer care may be better than in other African settings, ${ }^{[24]}$ making these findings less generalisable to other African settings.

\section{Conclusions}

Large national ART programmes like the one in SA can successfully reduce KS-related mortality at the individual patient level. If ART coverage is extended, KS-associated morbidity and mortality are likely to drop.

Acknowledgements. We thank the KS patients, medical oncology clinicians and administration at SBAH. We also thank thank Mamiki Modipa for assistance with data capture and Kali Tal for her editorial assistance. Author contributions. MMS wrote the protocol, collected data, performed statistical analysis and wrote the first draft of the manuscript; LD and DK conceived the study and contributed to the writing of the manuscript; and $\mathrm{JB}$ and ME contributed to the writing of the manuscript.

Funding. MMS's $\mathrm{PhD}$ work was funded by the International Epidemiology Databases to Evaluate AIDS in Southern Africa (IeDEA SA), grant no. U01AI069924 from the National Institutes of Health (National Institute of Allergy and Infectious Diseases, National Institute of Child Health and Human Development, National Cancer Institute) (principal investigators: Egger and Davies). The study was supported by the Swiss National Science Foundation (Ambizione-PROSPER fellowship PZ00P3_160407, principal investigator: Bohlius). The funders had no role in study design, data collection and analysis, decision to publish, or preparation of the manuscript.

\section{Conflicts of interest. None.}

\footnotetext{
1. Mosam A, Uldrick TS, Shaik F, Carrara H, Aboobaker J, Coovadia H. An evaluation of the early effects of a combination antiretroviral therapy programme on the management of AIDS-associated Kaposi's sarcoma in KwaZulu-Natal, South Africa. Int J STD AIDS 2011;22(11):671-673. https://doi. org/10.1258/ijsa.2009.009145

2. Engels EA, Biggar RJ, Hall HI, et al. Cancer risk in people infected with human immunodeficiency virus in the United States. Int J Cancer 2008;123(1):187-194. https://doi.org/10.1002/ijc.23487

3. Polesel J, Franceschi S, Suligoi B, et al. Cancer incidence in people with AIDS in Italy. Int J Cancer 2010;127(6):1437-1445. https://doi.org/10.1002/ijc.25153
}

4. Franceschi S, Lise M, Clifford GM, et al. Changing patterns of cancer incidence in the early- and late-HAART periods: The Swiss HIV Cohort Study. Br J Cancer 2010;103(3):416-422. https://doi. org/10.1038/si.bjc. 6605756

5. Shisana O, Rehle T, Simbayi L, et al. South African National HIV Prevalence, Incidence and Behaviour Survey, 2012. Cape Town: Human Sciences Research Council, 2014. http://www.health-e.org.za/wpcontent/uploads/2014/04/HRSC-2012.pdf (accessed 25 August 2017)

6. Johnson LF. Access to antiretroviral treatment in South Africa, 2004 - 2011. South Afr J HIV Med 2012;13(1):22-27. http://sajhivmed.org.za/index.php/hivmed/article/view/156 (accessed 25 August 2017).

7. Adam MA, Johnson LF. Estimation of adult antiretroviral treatment coverage in South Africa. S Afr Med J 2009;99(9):661-667. https://www.ncbi.nlm.nih.gov/pubmed/20073293

8. Chu KM, Mahlangeni G, Swannet S, Ford NP, Boulle A, van Cutsem G. AIDS-associated Kaposi's sarcoma is linked to advanced disease and high mortality in a primary care HIV programme in South Africa. J Int AIDS Soc 2010:13(1):23. https://wwwncbi.nlm nih gov/pmc/articles/PMC2914751/

9. Mosam A, Shaik F, Uldrick TS, et al. A randomized controlled trial of highly active antiretroviral Mosam A, Shaik F, Uldrick TS, et al. A randomized controlled trial of highly active antiretroviral
therapy versus highly active antiretroviral therapy and chemotherapy in therapy-naive patients with HIV-associated Kaposi sarcoma in South Africa. J Acquir Immune Defic Syndr 2012;60(2):150-157. HIV-associated Kaposi sarcoma in South Africa.

10. Herce ME, Kalanga N, Wroe EB, et al. Excellent clinical outcomes and retention in care for adults with HIV-associated Kaposi sarcoma treated with systemic chemotherapy and integrated antiretroviral therapy in rural Malawi. J Int AIDS Soc 2015;18(1):19929. https://doi.org/10.7448/ias.18.1.19929

11. Sissolak G, Mayaud P. AIDS-related Kaposi's sarcoma: Epidemiological, diagnostic, treatment and control aspects in sub-Saharan Africa. Trop Med Int Health 2005;10(10):981-992. https://doi. org/10.1111/j.1365-3156.2005.01491.x

12. Krown SE, Testa MA, Huang J. AIDS-related Kaposi's sarcoma: Prospective validation of the AIDS Clinical Trials Group staging classification. AIDS Clinical Trials Group Oncology Committee. J Clin Oncol 1997:15(9):3085-3092. https://doi.org/10.1200//CO.1997.15.9.3085

13. Bohlius J, Valeri F, Maskew M, et al. Kaposis sarcoma in HIV-infected patients in South Africa: Multicohort study in the antiretroviral therapy era. Int J Cancer 2014;135(11):2644-2652. https://doi. org $/ 10.1002 /$ ijc.28894

14. Lodi S, Guiguet M, Costagliola D, Fisher M, de Luca A, Porter K. Kaposi sarcoma incidence and survival among HIV-infected homosexual men after HIV seroconversion. J Natl Cancer Inst 2010;102(11):784-792. https://doi.org/10.1093/jnci/djq134

15. El Amari EB, Toutous-Trellu L, Gayet-Ageron A, et al. Predicting the evolution of Kaposi sarcoma, in the highly active antiretroviral therapy era. AIDS 2008;22(9):1019-1028. https://doi.org/10.1097/ gad.0b013e $3282 \mathrm{fc} 9 \mathrm{c} 03$

16. Bhutani M, Polizzotto MN, Uldrick TS, Yarchoan R. Kaposi sarcoma-associated herpesvirus-associated malignancies: Epidemiology, pathogenesis, and advances in treatment. Semin Oncol 2015;42(2):223246. https://doi.org/10.1053/j.seminoncol.2014.12.027

17. Phipps W, Ssewankambo F, Nguyen $H$, et al. Gender differences in clinical presentation and outcomes of epidemic Kaposi sarcoma in Uganda. PLoS One 2010;5(11):e13936. https://doi.org/10.1371/journal. pone. 0013936

18. Mosam A, Hurkchand HP, Cassol E, et al. Characteristics of HIV-1-associated Kaposi's sarcoma among women and men in South Africa. Int J STD AIDS 2008;19(6):400-405. https://doi.org/10.1258/ ijsa. 2008.00730

19. National Department of Health, South Africa. National Antiretroviral Treatment Guidelines. Pretoria: NDoH, 2004. http://apps.who.int/medicinedocs/documents/s17758en/s17758en.pdf (accessed 16 January 2017).

20. Rohner E, Valeri F, Maskew M, et al. Incidence rate of Kaposi sarcoma in HIV-infected patients on antiretroviral therapy in southern Africa. J Acquir Immune Defic Syndr 2014;67(5):547-554. https:// doi.org/10.1097/qai.0000000000000360

21. Cullinan K. South Africa moves to 'test and treat'. Health-E News 10 May 2016. https://www.health-e, org.za/2016/05/10/south-africa-moves-test-treat/ (accessed 16 January 2017).

22. Shisana O, Zungu N, Evans M, Risher K, Rehle T, Clementano D. The case for expanding the definition of 'key populations' to include high-risk groups in the general population to improve targeted HIV prevention efforts. S Afr Med J 2015;105(8):664-669. https://doi.org/10.7196/saminew.7918

23. Delgado-Rodríguez M, Llorca J. Bias. J Epidemiol Community Health 2004;58(8):635-641. https://doi, org/10.1136/jech.2003.008466

24. Kingham TP, Alatise OI, Vanderpuye V, et al. Treatment of cancer in sub-Saharan Africa. Lancet Oncol 2013;14(4):e158-e167. https://doi.org/10.1016/s1470-2045(12)70472-2

Accepted 10 April 2017 